\title{
O layout como fator constitutivo dos quadrinhos: o caso Alexandre S. Lourenço
}

\author{
Daniel Baz dos Santos
}

Em "Robô esmaga", Alexandre Lourenço apresenta uma série de trabalhos que podem ser definidos dentro do gênero "tira", ainda que o alto grau de experimentalismo e subversão do discurso em suas histórias as encaminhe para territórios nos quais as definições e os princípios taxonômicos de toda sorte se tornam imprecisos ou mesmo ineficazes. A esse respeito, pode-se considerar que Lourenço participa do legado aberto por Laerte, que inaugurou no país um desdobramento do gênero "tira", a "tira livre". Segundo Paulo Ramos, ainda que sempre tenham existido autores que buscaram certo experimentalismo e, por vezes, abdicaram do humor em suas tirinhas, no Brasil, o novo formato foi popularizado a partir de 2005, ainda na série "Piratas do Tietê".

Nos primeiros 19 meses, entre março de 2005 e outubro de 2006, já se podiam observar algumas marcas do novo modo de produção de tiras. Havia a presença de personagens não fixos, usados apenas para construção daquela história. A tendência era a de não adotar a estrutura tradicional das tiras cômicas, com a presença de uma piada ao final. O humor também era deixado de lado. No lugar, trabalhavam-se temas dos mais variados. Em parte das tiras, a construção do sentido aproximava-se do que o escritor e semiólogo italiano Umberto Eco chamou de "obra aberta", ou seja, cabia ao leitor a tarefa de impor a interpretação. Esses aspectos, das liberdades temática, estilística e de interpretação, aproximam as tiras de Laerte dos campos da poética e da filosofia. Outro diálogo possível, como o próprio desenhista explicitava no capítulo anterior, era com a crônica. Esta é entendida justamente por transitar entre os universos literário e jornalístico, a depender do olhar que se dê a ela, e por ter uma maleabilidade constitutiva (RAMOs, 2014, p. 23-24).

Alexandre S. Lourenço se insere dentro deste novo panorama, que também será perseguido (parcial ou integralmente) por nomes como André Dahmer, Daniel Lafayette e José Aguiar, no qual as tiras, desvinculadas das fórmulas ligadas exclusivamente à produção de humor, se focam em abrigar temas mais diversificados e ambiciosos. Na obra de Lourenço, avultam, por exemplo, pensamentos so-

Doutor em Letras pela Universidade Federal do Rio Grande do Sul (UFRGS) e professor do Instituto Federal de Educação do Rio Grande do Sul - Campus Rio Grande, Brasil. E-mail: dbazdossantos@yahoo.com. 
bre a existência, sobre a brevidade da vida, sobre as tomadas de decisão diante do mundo, entre outros conteúdos éticos, sociais e existenciais. Considere-se a narrativa intitulada "Trabalho" (LouRenço, 2014, p. 59). Ela se constitui em 57 quadros dispostos em oito linhas horizontais e oito verticais. No entanto, a última linha apresenta apenas um quadro, situado no canto inferior direito da página. Esses quadros são desenhados exatamente da mesma forma e mostram o personagem trabalhando diante de um objeto que lembra a tela de um computador.

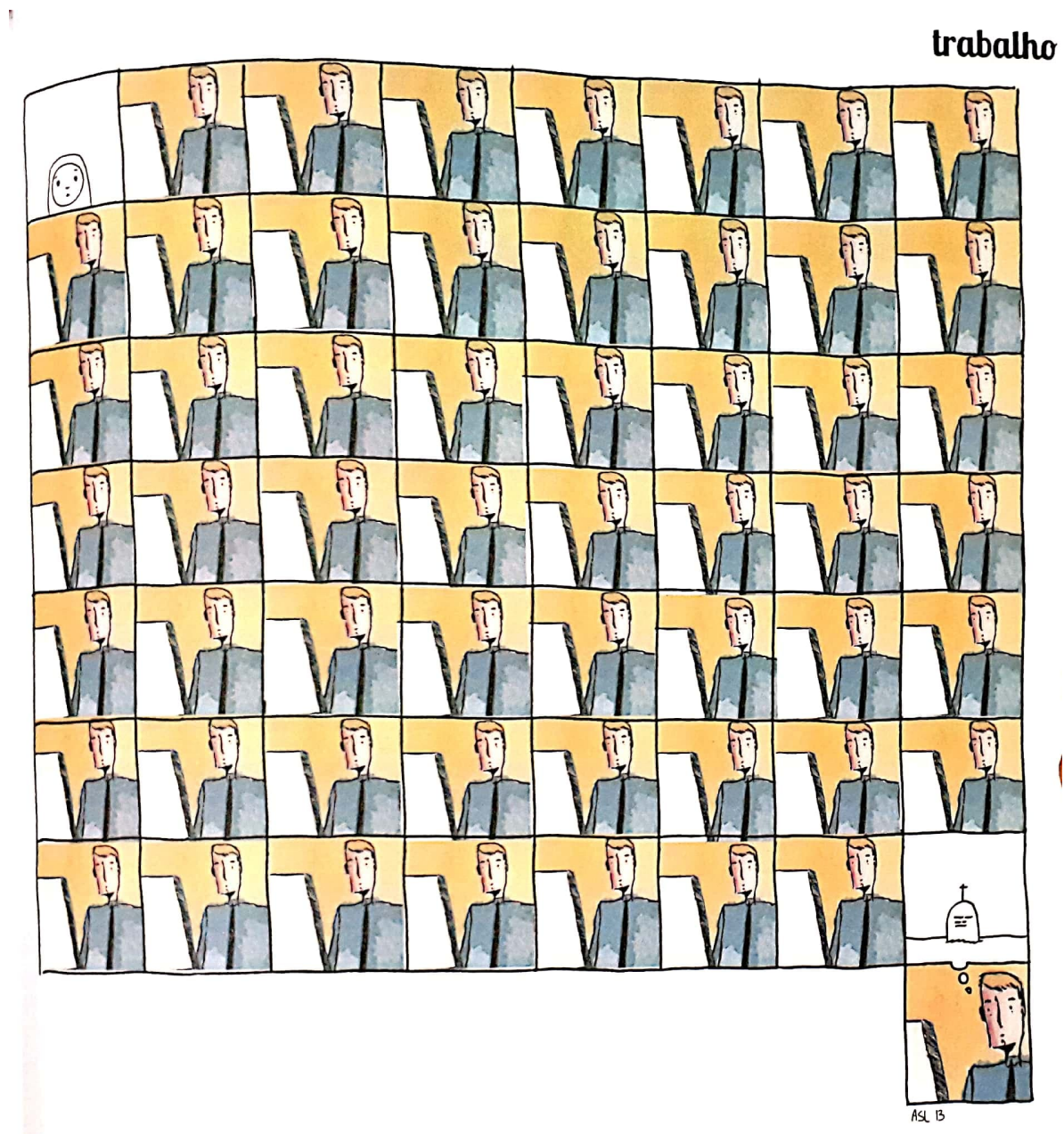

FigurA 1

Este objeto é desenhado a partir de três procedimentos bem simples. Uma linha superior fina, uma borda à direita, um pouco mais grossa, e um preenchimento branco. Este branco só aparecerá em outras duas oportunidades na história, justamente em dois dos quadros que destoam dos demais: o primeiro e o de número 56. Por ser uma das poucas narrativas coloridas do livro, a ausência de cores enfatiza a natureza diferenciada dessas duas imagens. Na primeira, há o rosto de uma criança, também desenhado de forma simplificada, ao passo que, no penúltimo qua- 
dro, há a representação de uma lápide, sinalizando, assim, para a infância e óbito do protagonista. Abaixo dele, um apêndice de balão de pensamento se conecta ao último quadro da história, onde há uma aproximação em close da personagem, que continua na mesma posição.

O alto número de conteúdos idênticos dentro dos quadros constrói dois efeitos distintos. O primeiro, da ordem do simbólico, ressignifica o título dado à narrativa, "Trabalho", e permite que compreendamos a lógica estética/ética por trás do estrato propositivo mais evidente da obra, isto é, uma constatação negativa a respeito da prática laboral estafante, monótona, repetitiva e apática do personagem, responsável por gastar integralmente sua vida. Aqui estamos apenas no nível ético de leitura da história. Para entendê-la em linhas mais complexas, é preciso notar que nela há uma certa perversidade na reiteração obsessiva da mesma imagem, fenômeno que tem por base o próprio ato de quadrinizar, isto é, de produzir em massa um elevado número de quadros exatamente iguais, de forma mecânica e aparentemente imparcial, como se o produto criativo tivesse sido produzido em uma linha de montagem. Melhor dizendo, como se criar pudesse ser tão entediante quando o ofício do sujeito retratado.

Se lemos "Robô esmaga" na ordem em que as histórias se apresentam, esse sentido já nos é conhecido em forma de latência, posto que a narrativa "Como fazer quadrinhos", que abre o livro e que também é construída com pouquíssimas variações figurativas, introduz algumas das noções que serão exploradas em "Trabalho". De fato, ambas as histórias podem ser consideradas irmãs, posto que, nesta última, somos apresentados a um sujeito, visto em uma perspectiva lateral, que trabalha diante de uma mesa de desenho. Depois de 17 quadros rigorosamente iguais, no primeiro quadro da última tira, um balão repleto de reticências, seguido da posição reflexiva adquirida pelo indivíduo, revelam um momento de provável inspiração. Dois quadros depois, ele retorna ao trabalho, e as imagens voltam a ser todas iguais.

Em "Trabalho" a tônica é a mesma e também sinaliza para a prática exaustiva e iterativa de produzir quadrinhos. Talvez por conta disso, a biografia de Alexandre S. Lourenço apresentada ao final do livro seja feita também na forma de narrativa gráfica, lembrando muito a dinâmica de "Como fazer quadrinhos". Sendo assim, até mesmo na hora de se apresentar ao público, o autor nos expõe aquela que parece ser a face mais padronizada, insensível e letárgica de sua atividade. Em "Trabalho", por sua vez, essa relação entre o ato criativo e os conteúdos diegéticos é reforçada ainda pelo branco no interior da tela na qual o sujeito trabalha, ou seja, tem-se aqui uma evocação da alvura do papel no qual os quadrinhos são elaborados e geralmente impressos e que representa o momento anterior ao ato criativo, no qual as formas ainda não foram desenhadas, nada foi decidido, e tudo é potência.

São esses aspectos que orientam nosso olhar para a confecção técnica da obra, em chave metalinguística, e que nos inserem no terreno do segundo efeito obtido 


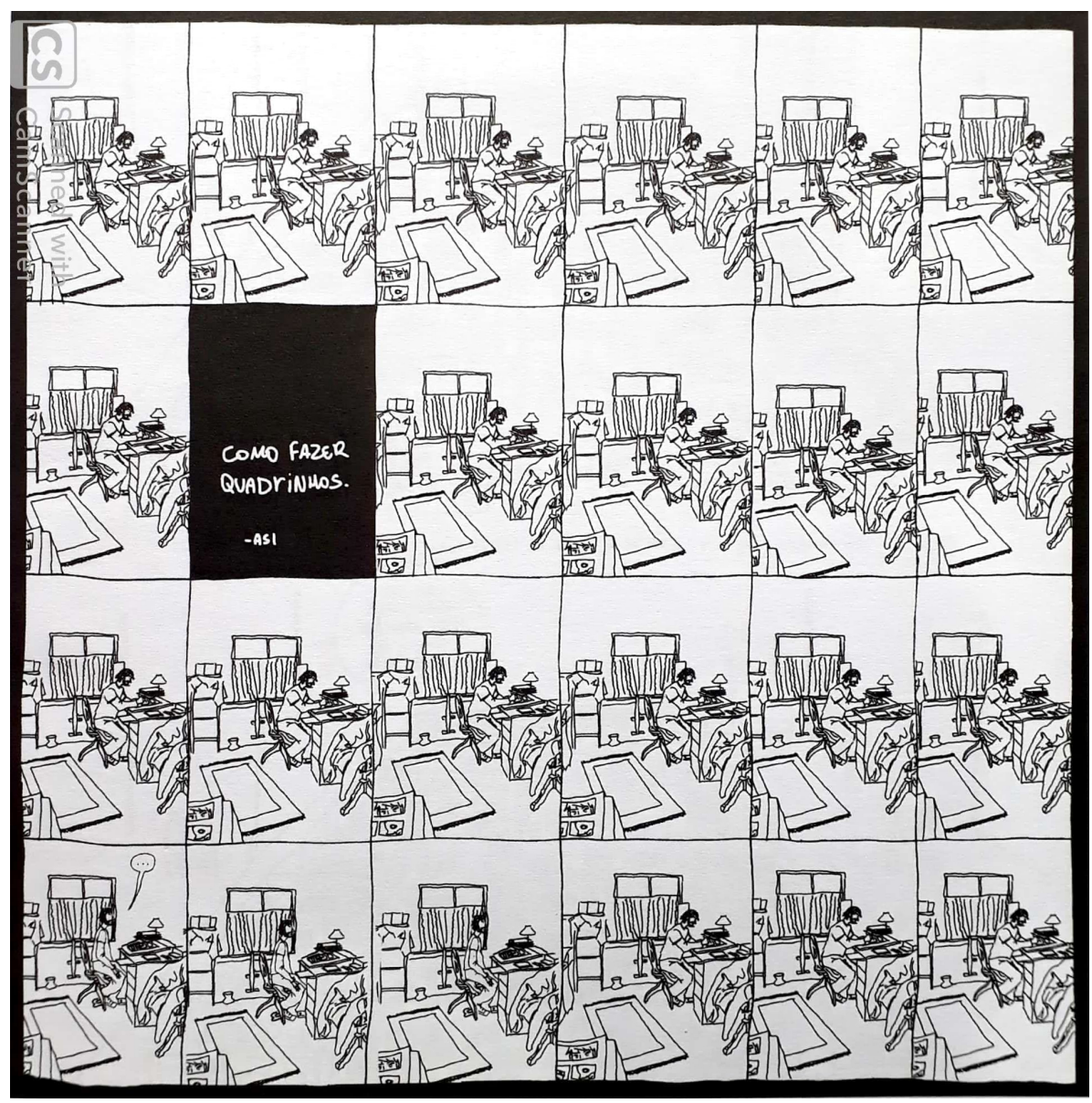

Figura 2

pelo processo de reiteração da mesma imagem, posto que, ao perdermos o interesse pelo desenho em si, voltamos nossa atenção para a disposição dos quadros. Além disso, durante a leitura de "Trabalho", existem grandes chances de uma passada de olhos na página indicar seu caráter reiterativo antes de terminarmos a leitura quadro a quadro. Talvez seja correto dizer que dificilmente o leitor se dará ao trabalho de observar cada uma das imagens de forma independente, a não ser que busque encontrar discrepâncias entre elas, o que não conseguirá. A história convida, portanto, que ignoremos, em certa parte, seus ícones de composição e foquemos na relação existente entre eles ao longo da prancha. Por esta via, somos conduzidos naturalmente em direção à análise do layout, isto é, da organização dos quadros na página, fator decisivo na construção de boa parte dos sentidos das histórias de Alexandre Lourenço.

Em "Trabalho", a passagem de um quadro a outro sinaliza uma mudança de ordem temporal. O real impacto dessa mudança se processa na "sarjeta", o espaço entre quadros. Como não há nenhuma mudança icônica nas figuras, não existem in- 


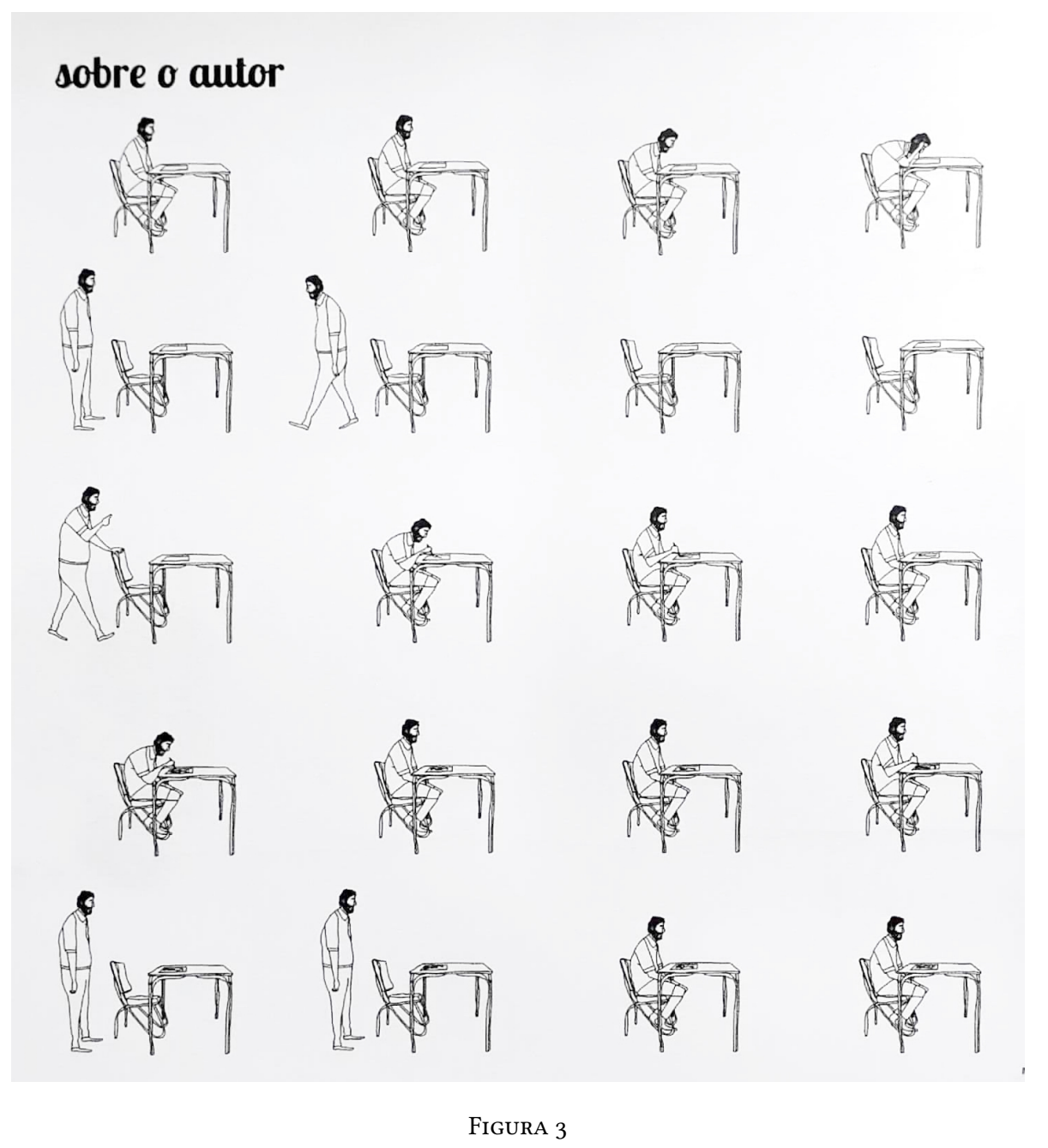

formações novas a serem processadas, nem desdobramentos discursivos, linguísticos ou narrativos inerentes ao desenho. Todo sentido novo surge de uma relação de posicionamento, que respeita principalmente uma lógica serial. O único elemento que poderia nos fazer perceber a contiguidade das cenas de maneira diferente seria o quadro inicial, mas até que cheguemos ao fim da história, não possuímos repertório suficiente para compreender suas reais acepções. Quando finalmente lemos os dois últimos quadrinhos, outros potenciais semânticos se desvelam. No último quadro da sétima linha, apresenta-se o túmulo do protagonista. Se fossemos parafrasear o significado da tira em uma narrativa simples, como forma de nos orientarmos sobre seu enredo, poderíamos concluir que ela propõe algo do tipo: "Nascer, trabalhar, trabalhar, trabalhar... morrer".

Contudo, a última imagem ainda está por vir. Na construção sequencial dos episódios de "Trabalho", a representação da morte não é o ponto final, o que torna 
sua presença mais angustiante, posto que é um item alinhado com naturalidade aos demais atos descritos pela narrativa. No último quadro, por sua vez, aquele que se destaca de todos os outros, vemos o personagem de uma perspectiva mais próxima, como se pudéssemos o acessar de uma forma mais íntima, abrindo-nos para seus pensamentos. Este quadro está desconectado da série e paira sozinho no canto da página. Isso implica aceitar que a conscientização do personagem é um momento que não se circunscreve em sua rotina ou é estranha a ela, sendo ponto anômalo nos processos de sucessão que configuram o sentido da narrativa. Neste ponto, entram em choque, na página, alguns fundamentos estéticos dos quadrinhos, que podem ser devidamente desbravados com a ajuda do pensamento teórico de Thierry Groensteen.

O autor parte da noção de "solidariedade icônica" para definir a dinâmica básica dos itens que atuam dentro de uma página de HQ e suas múltiplas formas de relacionamento. Tendo isso em vista, Groensteen utiliza os conceitos de "artrologia" e de "espaçotopia" para sustentar sua abordagem das narrativas gráficas. Em suas palavras:

As histórias em quadrinhos apresentam as imagens que as compõem em diferentes tipos de relação. Para qualificar o conjunto dessas relações, utilizarei um termo genérico com significado amplo: Artrologia (do grego arthron: articulação). Qualquer imagem desenhada encarna-se, existe, implanta-se em um espaço. Contrariamente à imagem em movimento do cinema, que Gilles Deleuze demonstrou ser ao mesmo tempo 'imagem-movimento' e 'imagem-tempo', a imagem fixa conhece apenas a primeira dimensão. Vincular os quadros dos quadrinhos consiste necessariamente em vincular os espaços, operar em um espaço compartilhado. São estes os princípios fundamentais da distribuição espacial que serão examinados pela primeira vez sob a rubrica de espaçotopia, termo criado por reunir mesmo mantendo separados, os conceitos de espaço e de localização (Groensteen, 2015, p. 31).

Esta distribuição, no entanto, geralmente respeita as conexões internas da narrativa, que prezam pela conjunção e concatenação. Em vista disso, Groensteen completa:

As relações elementares, de tipo linear, fazem parte do que nomearemos de artrologia restrita. Regidas pela operação de decupagem, elas implementam sintagmas sequenciais, normalmente subordinados aos fins narrativos. É nesse nível que a escrita tem prioridade como operador complementar da narração. As outras relações, translineares ou distanciadas, pertencem à artrologia geral e compõem as modalidades do entrelaçamento (Groensteen, 2015, p. 32).

De acordo com o teórico francês, durante a leitura de uma história em quadrinhos é necessário, portanto, identificar o tamanho, forma e posição dos quadros, 
além dos processos atinentes à montagem por trás destes aspectos. São esses fenômenos que permitem a leitura profunda dos conteúdos intra-quadro. Ao pensarmos na história de Alexandre S. Lourenço, a partir da localização dos quadros, notamos que a rima entre o primeiro e o penúltimo fecha um ciclo preciso, o próprio ciclo da vida. Nesse sentido, o lugar do último quadro envolve um não pertencimento a esse ciclo, ao andamento natural das coisas, e, mais uma vez, nos permite inscrever seu substrato enunciativo dentro de uma ideia de rebeldia, de não participação e conscientização a respeito da lógica atroz da própria existência.

Como contraponto irônico, os quadros que compõe praticamente toda a narrativa associam a imobilidade do personagem e a ausência de um sintagma actancial diferenciado com a suspensão momentânea da morte. O processo de leitura em direção ao penúltimo quadro implica conduzir o personagem, em termos icônicos, à própria morte, como um jogo de tabuleiro sinistro, cujo prêmio é a desdita. Além disso, os dois quadros em preto e branco, estando nos pontos iniciais e finais desse processo, ressaltam ainda mais sua alienação, pois manifestam o mundo essencialmente imaginativo do protagonista, seus anseios e preocupações, algo que não cabe dentro da vida automatizada que seu trabalho exige.

Essa estase interna dos 54 quadros idênticos, em que nada parece acontecer, tem também uma natureza narrativa, posto que, como já afirmou Roger Odin: "Uma imagem fixa pode ter estrutura narrativa: basta que a vetorização corresponda a uma estrutura actancial de categoria conflitiva entre sujeito e anti-sujeito ou as relações entre um sujeito e objeto de desejo." (Groensteen, 2015, p. 111). Sendo assim, ao voltarmos nosso olhar para o desenho, verificamos que a relação entre o indivíduo e a tela diante si, o de sujeito observador e objeto observado, se converte não somente na do autor diante de sua prancha em branco, mas, de forma paródica, na do intérprete diante da busca de sentido da narrativa, atento às relações espaçotópicas da página e a configuração enunciativa de seu layout. É a partir desta posição ambivalente que partimos para a análise de outros textos de Alexandre S. Lourenço apresentados em "Robô esmaga".

Como antecipamos, ainda que a imagem, seus ícones e sua sequencialidade sejam elementos fundamentais na obra de Alexandre S. Lourenço, de todos os elementos que operam no interior das páginas idealizadas por ele, o layout parece ser o eixo do processo de significação de muitas de suas histórias. Na maioria das vezes, somente quando percebemos o que está "à esquerda", "à direita", e, principalmente, "em cima" ou "em baixo" nas suas páginas/quadros é que podemos iniciar o processo de decodificação de seu sentido.

Neste ponto, é necessário lembrar que estas tiras foram inicialmente publicadas como web comics, o que certamente favoreceu várias das liberdades tomadas pelo quadrinista, especialmente no que diz respeito à quebra de alguns limites formais, como veremos. Com efeito, um dos recursos mais utilizados pelo autor envolve colocar em conflito os extratos superiores e inferiores no interior das composições, constituindo crises que ressaltam o todo simbólico da leitura vetorial a partir do 
choque entre os valores da horizontalização e da verticalização. De acordo com Groensteen:

Assim, quando o layout segue a divisão canônica entre tiras devidamente apartadas, a leitura da história em quadrinhos segue um ritmo natural, uma respiração suscitada por seu dispositivo discreto de enunciação, escalonando e tabular. Seguindo na comparação com o âmbito musical, podese dizer que a tira é uma medida - mas uma medida irregular, já que a duração dos quadros não é constante (Groensteen, 2015, p. 69).

Em vista disso, o autor conclui de forma taxativa:

Quando o layout é irregular, essa respiração é prejudicada, torna-se anárquica ou, quem sabe desaparece por completo como fenômeno de condução da leitura. Se a página pode, com isto, ganhar em expressividade, imagina-se que, de forma correspondente, algo se perde no poder de fascínio hipnótico exercido pela ficção desenhada. Aliás, produzemse simultaneamente dois efeitos que têm o mesmo sentido. A transformação do layout em performance ostensiva (em vez de um dispositivo aparentemente neutro, que assim tenta à transparência) que desvia, a favor dos parâmetros formais, uma parcela de atenção que, de outra forma, voltar-se-ia inteiramente para o conteúdo narrativo; e ao mesmo tempo desfaz essa captura do leitor pelo ritmo, sobre a qual apoia-se, mesmo que ingenuamente, a maior parte das HQs tidas como clássicas (Groensteen, 2015, p. 70).

Em "Robô esmaga" são muitas as histórias repletas de jogos espaciais diversos, como "Centro do universo" (Lourenço, 2014, p. 43), ou "Mas nunca", que apresenta o indubitável texto "Nunca, mas nunca, olhe para baixo" (LourENçO 2014, p. 51), entre outras composições de mesmo tipo. Em relação aos projetos que enaltecem a linha horizontal, abundam as narrativas que utilizam o espaço da página dupla, trabalhos que enfatizam as forças de afastamento e de concatenação que atuam na confecção de uma história em quadrinhos. Para ilustrar estes artifícios, pode-se citar "Balão" (Lourenço, 2014, p. 44-45) ou "Kriptnonita" (Lourenço, 2014, p. 72-75). Nesta, como no caso extremo de "8o", a verticalização e a horizontalização da página criam um nó paradoxal, posto que devemos virar o quadrinho para ler o conteúdo disposto nele, no segundo caso, regido pelo personagem agigantado que atravessa as margens de uma página a outra (LOURENÇO, 2014, p. 10-11).

No entanto, algumas histórias de Lourenço obrigam nosso olhar a atentar para o percurso do alto/para baixo da leitura. Vejam-se narrativas como "Olhe pra cima" (Lourenço, 2014, p. 38) ou "Não pare, Lopes" (LourençO, 2014, p. 58). A primeira, mais explícita, esconde um balão (item muito utilizado pelo autor e que simboliza justamente o aéreo, a desatenção, a capacidade de procurar/olhar para lugares 


\section{centro do universo}

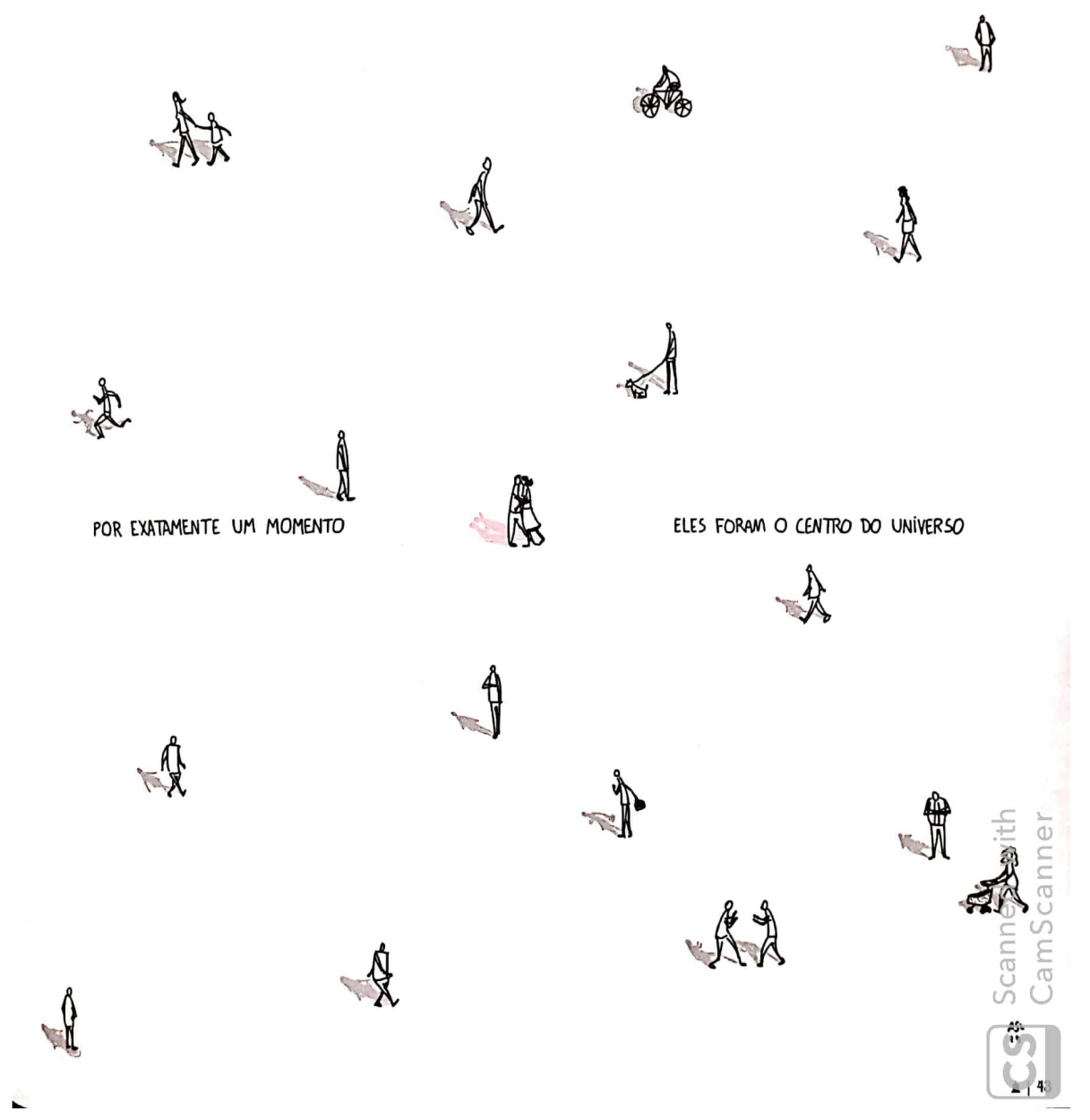

FigURA 4

inesperados, inéditos, imprevistos e instintivos) em segmento do canto superior direito da página.

Já no segundo exemplo, vemos um personagem caminhando sobre pesada chuva (outro elemento muito comum nas histórias de Lourenço e que também sinaliza para conexões íntimas entre o que está "acima" e o que está "abaixo" no quadro). Em um texto posicionado no lastro superior da página - já que o autor evita o uso de recordatórios, o que acarreta a intrusão dos sintagmas verbais sob os visuais, exigindo que ele encontre seu espaço dentro do material imagético à disposição - é possível ler a frase "Não pare, Lopes". A sentença já está presente no título da história e paira sobre a personagem no segundo quadro como uma espécie de consciência cósmica para, depois de uma interrupção da caminhada 


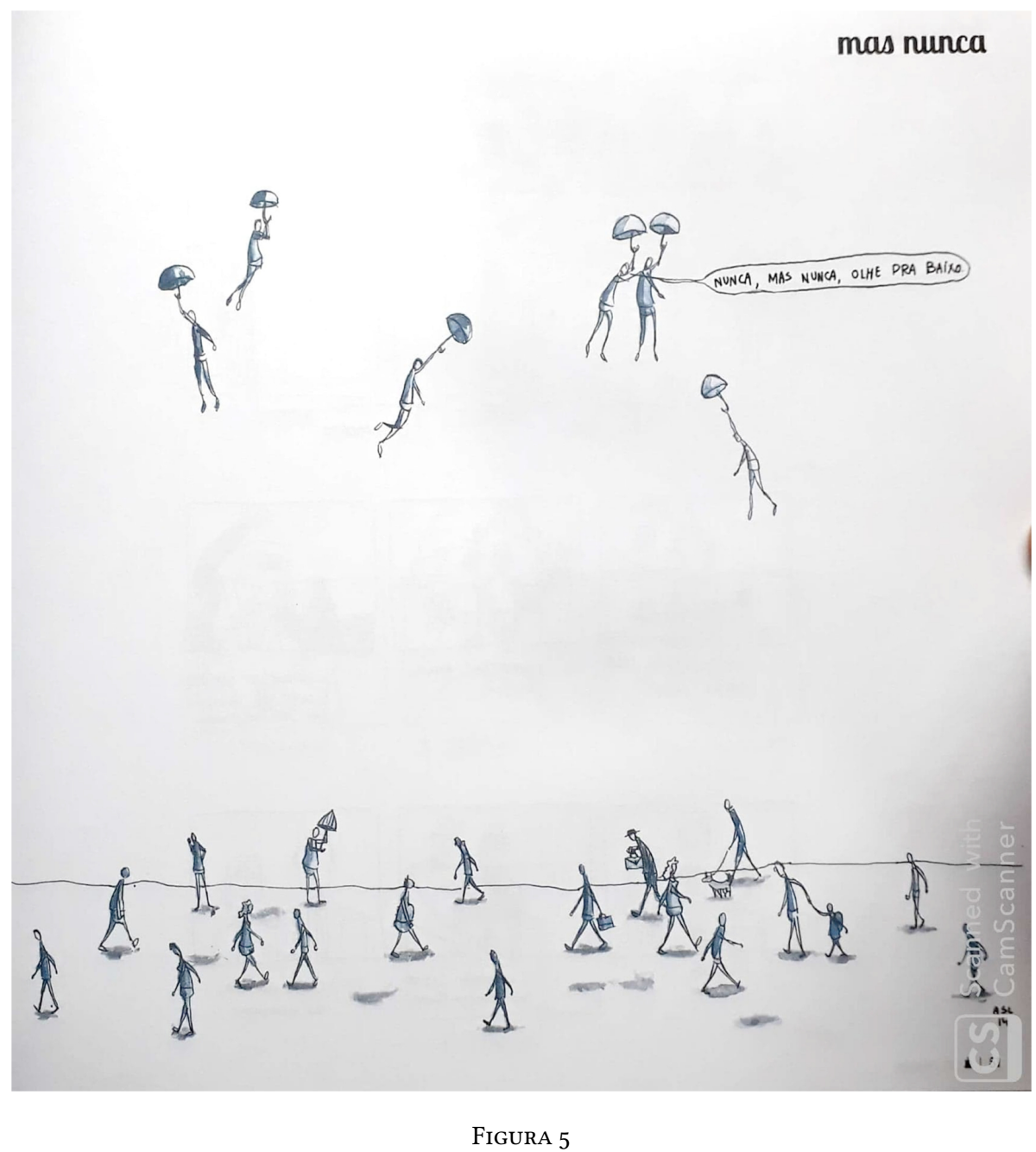

da personagem no terceiro quadro, retornar dentro de um balão de texto, cujo conteúdo é expresso pelo próprio Lopes, no último quadro.

O balão agora paira no mesmo nível horizontal do sujeito, como se o seguisse enquanto ele se retira pelo canto do quadro, representando a internalização de um texto que antes era de ordem superior, que lhe era inacessível. O layout aqui é aparentemente simples. Os quatro quadros são separados por duas linhas, uma vertical e outra horizontal. Ao invés do espaço da sarjeta propriamente ditos, esta disposição se organiza em forma de "diagrama" (PostemA, 2018, p. 72), o que promove um equilíbrio angustiante, um desejo de harmonia e de estabilidade que escapam também ao personagem da história. Em outras palavras, aqui a artrologia serve para inscrever ao redor de Lopes um desejo de ordem e imobilidade que complementam, melancolicamente, o percurso dele ao longo da página. 


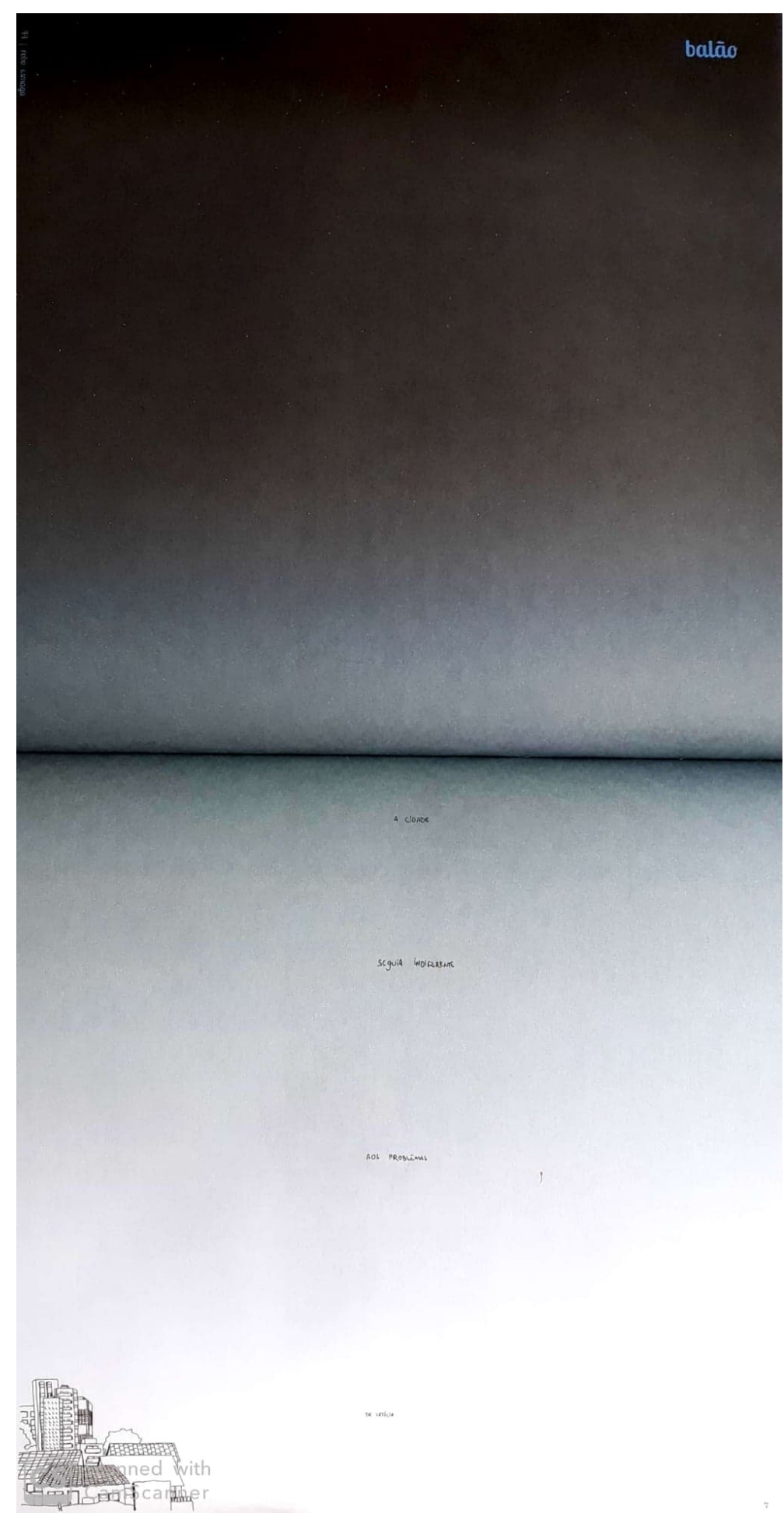

Figura 6 


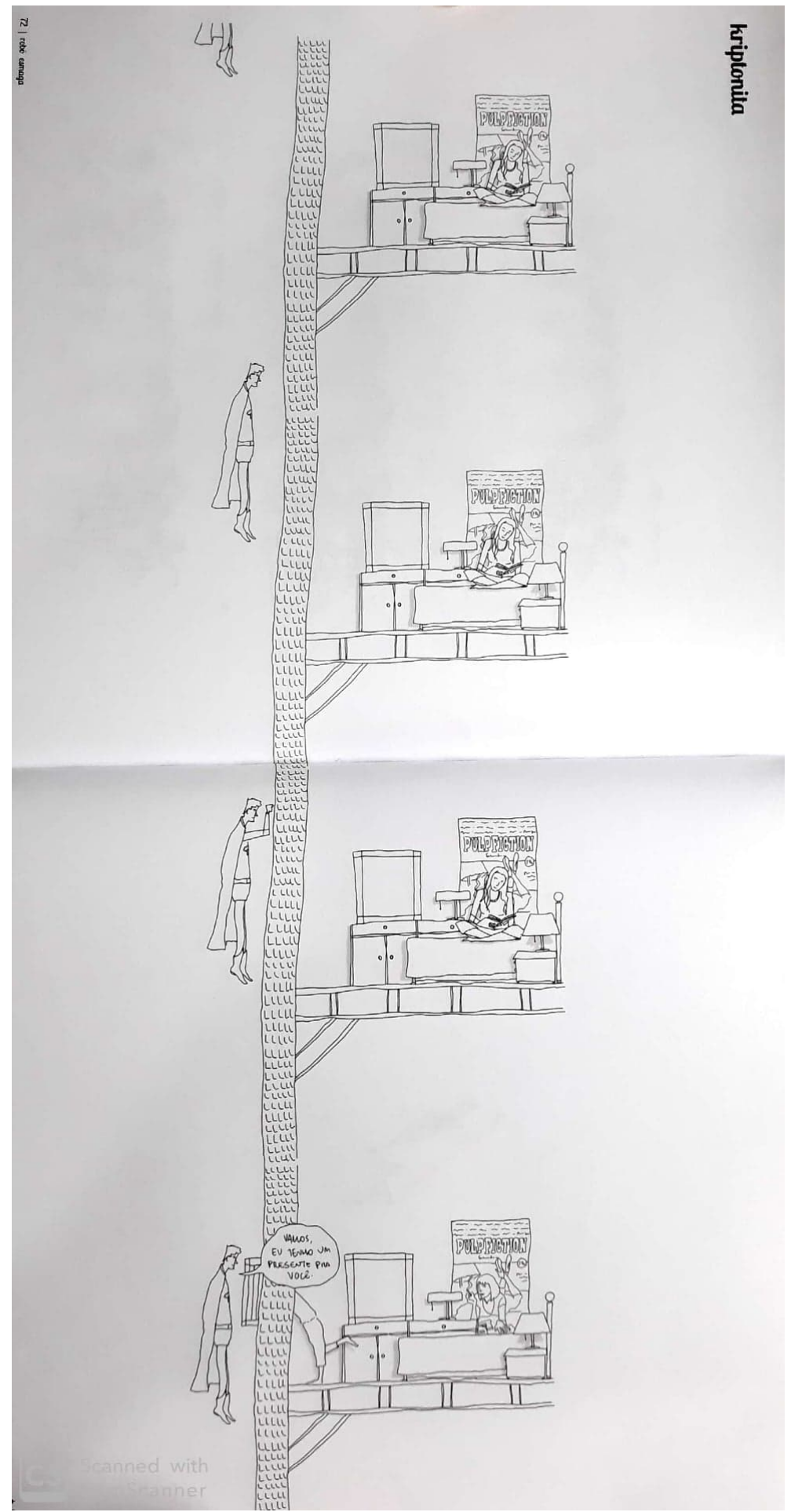

FIGURA 7 


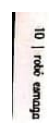

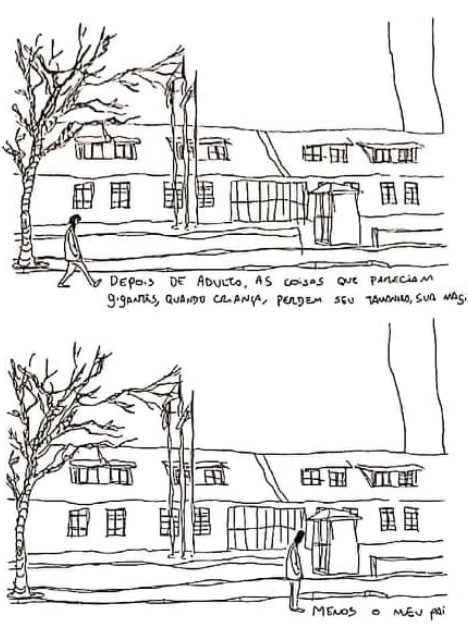

80

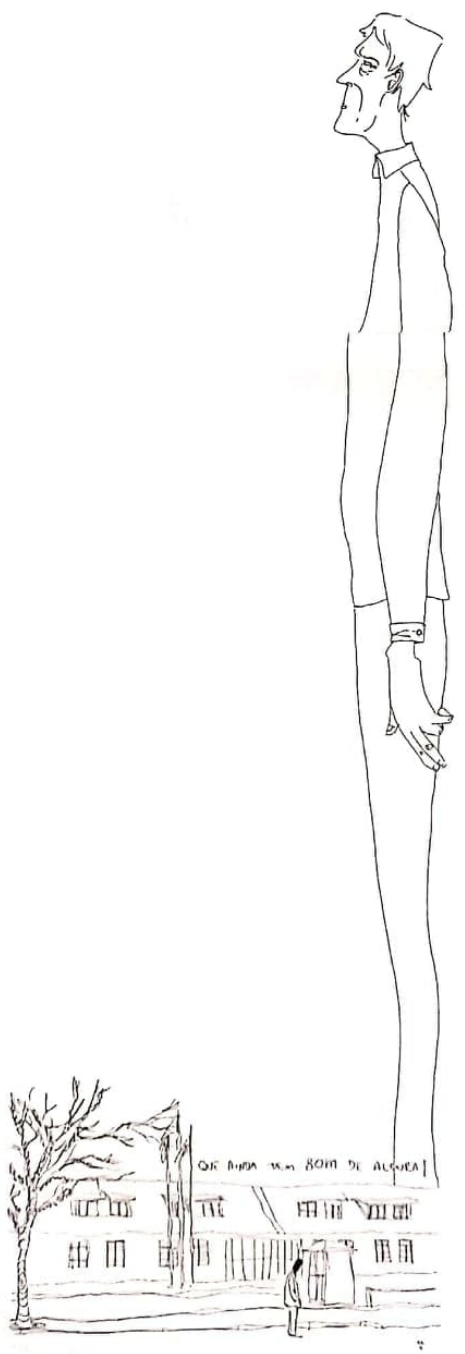

Figura 8 


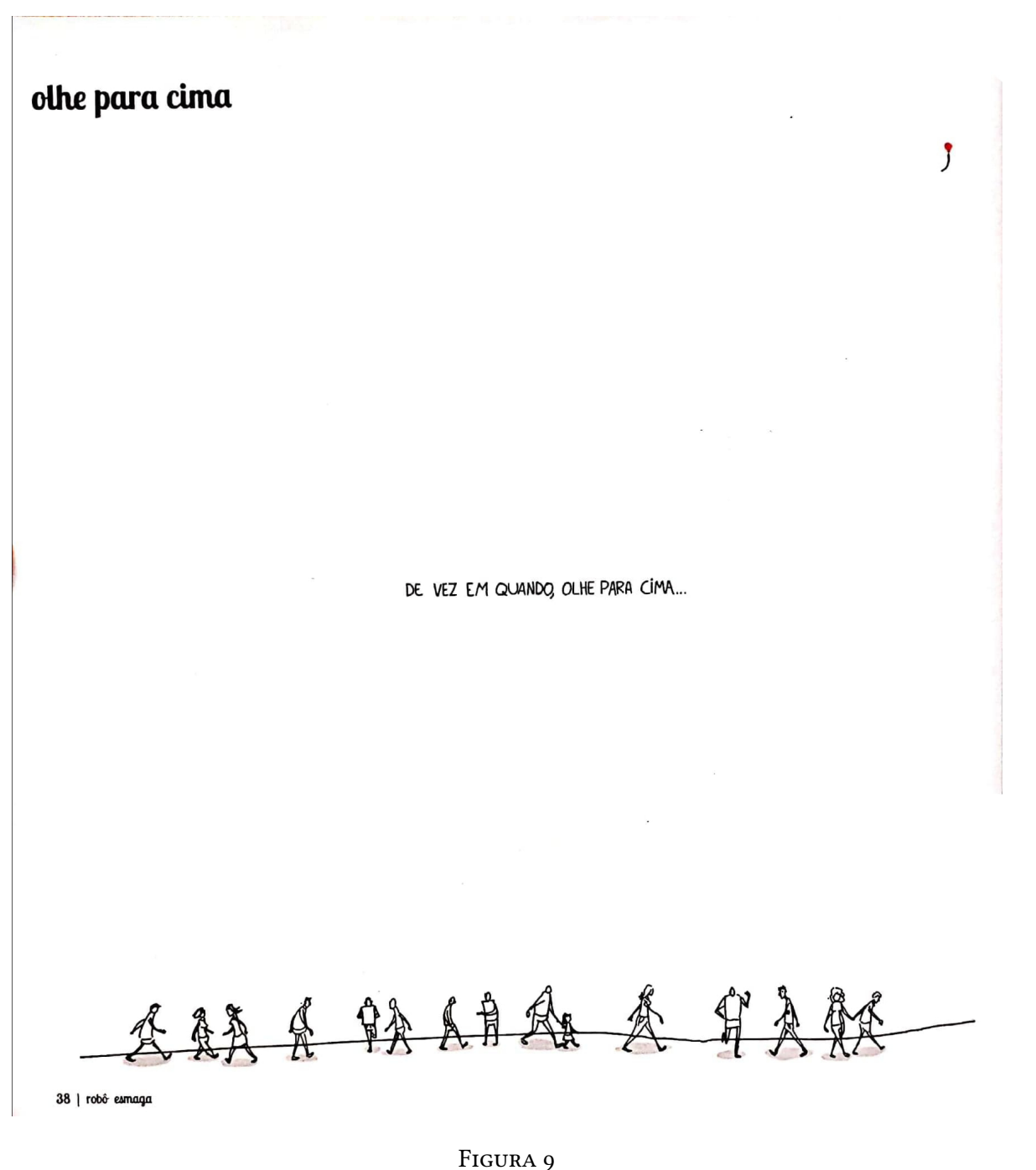

Outro item da ordem do layout que se constitui em cenário preferencial das histórias de Lourenço, surgindo em inúmeras oportunidades ao longo de "Robô esmaga", são as baias de escritório. A esse respeito, pode-se analisar a história "Isaías", feita em quatro páginas de oito quadros, seguindo o esquema regular de dois quadros por página. Dois sujeitos surgem em um ambiente repleto de baias, no qual várias pessoas trabalham. Um deles, após emitir um "Alô" e não receber nenhuma resposta, avisa: "Isaías! O diretor quer falar contigo". Após isso, balões de texto surgem de dentro de cada uma das baias, cada vez mais numerosos, indicando o que todos os funcionários respondem, em pé e em uníssono: "Eu sou o Isaías". Para além da paródia do filme "Spartacus", em que os escravos bradam "Eu sou Spartacus”, em ordem de defender e preservar o herói, e da crítica explícita às relações de poder em ambientes laborais, a história revela também outro aspecto da poética de Lourenço em particular, e das relações artrológicas e espaçotópicas 


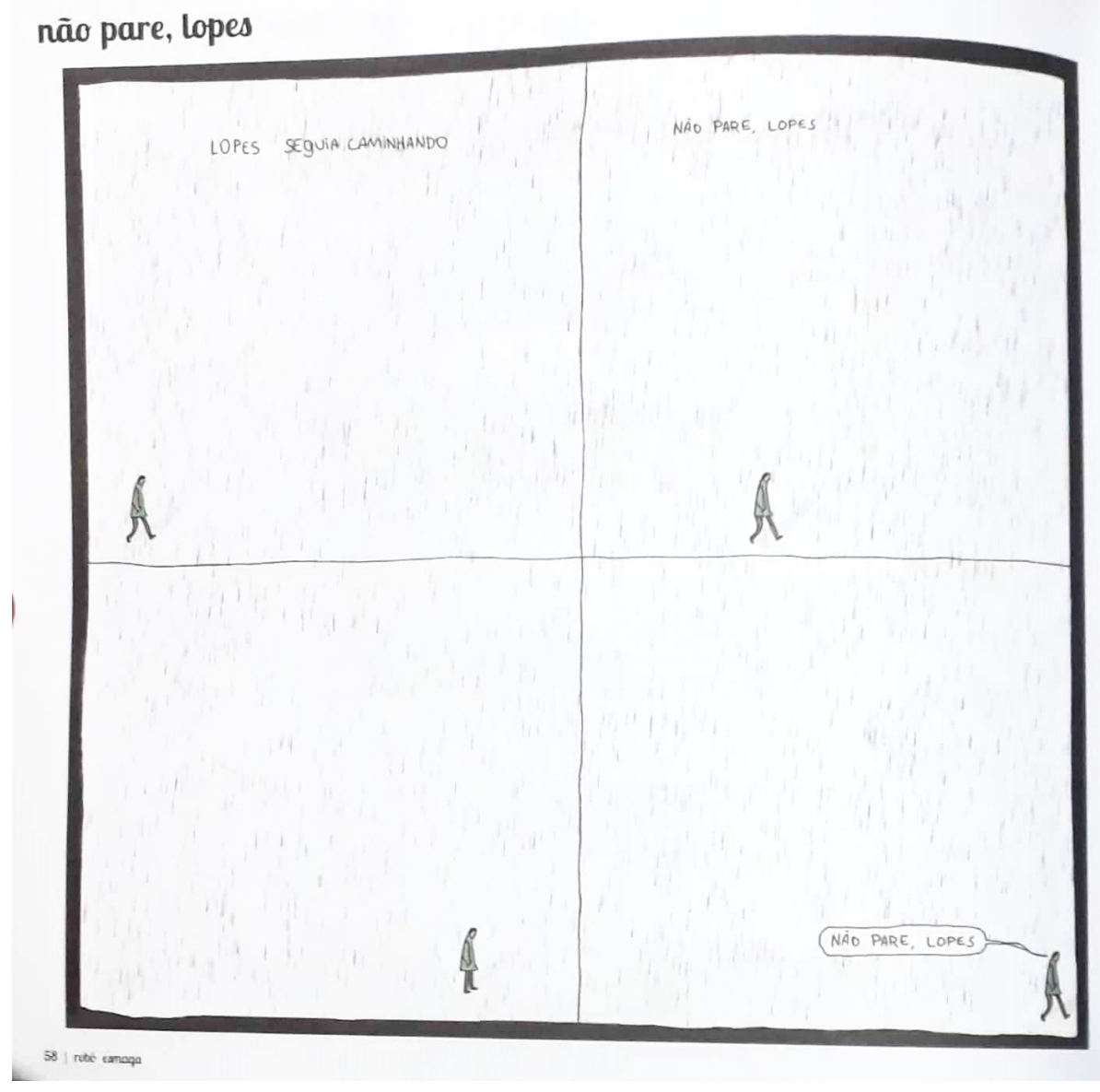

FigURA 10

dos quadrinhos em geral, recuperando esquemas que já analisamos aqui e apresentando novos.

Comecemos pelo olhar atento aos balões de texto na história abaixo (FIgURA 11). Como é comum em outras narrativas de Lourenço, os balões, além de destacar as falas das personagens, agem principalmente por intermédio da criação de novas rotas dentro do protocolo de leitura, assumindo dois papéis: ser o índice de uma presença e garantir uma coreografia específica do olho sobre a imagem. Tierry Groensteen analisa essas possibilidades a partir do seguinte comentário:

Quando um balão é colocado à distância do locutor (o que supõe um quadro provido de devidas altura e largura) e dado que essa distância vai contra a tendência natural, pode-se supor que isso acontece no contexto de uma intenção particular, na busca de um determinado efeito. Além do efeito específico que é produzido (que será, por exemplo, da ordem do entrelaçamento), observa-se comumente em tais casos que a distân- 
cia notável entre o balão e o locutor dá a impressão de que se interpôs um silêncio. Como se o balão não trouxesse mais que o eco de uma fala já dita, e que a personagem já retomou o silêncio. A partir dessa impressão (estou baseando-me aqui apenas na minha experiência pessoal como leitor), pode-se inferir que a imagem ordinariamente converte a simultaneidade de tempo em proximidade de espaço. Quando essa proximidade é respeitada, aliás, há um tempo particular que é dado ao binômio balãopersonagem, dado que, se diversos locutores coabitam o mesmo quadro e respondem um a outro, as tomadas de fala não podem ser sincrônicas, e cada um vive "a hora de seu balão" (Groensteen, 2015, p. 85).

Com base nessas afirmações, o teórico francês defende ainda que:

A questão é crucial, pelos motivos de que o balão talvez seja o único elemento do dispositivo página sobre o qual se pode ter certeza que o olhar vai parar (menos quando se folheia a HQ sem ler). Ele é uma âncora, uma passagem obrigatória. Assim, a leitura pode ser direcionada em certo sentido, conduzida pela rede que conecta as posições ocupadas pelos sucessivos balões. [...] Se os balões são apartados, podemos prever que o olhar pelo menos passará por cima da zona de imagem entre eles. É evidente que se pode fazer milhares de desvios entre um balão e outro; as posições dos balões indicam menos um caminho a seguir e mais etapas a se respeitar, entre as quais todo leitor tem a liberdade de vagar a seu bel-prazer, seguindo o que lhe solicitam outros estímulos (GROENSTEEN, 2015, p. 88).

Como não há requadro emoldurando a história, o balão é o limite superior do quadro, ou seja, é o limite até onde o olho deve ir, a margem do universo ficcional, o que, inicialmente, fortalece a sensação de rebeldia exposta pela fala das personagens, uma vez que as bordas que orbitam seu discurso criam a divisa icônica do mundo diegético. No entanto, não demora para percebermos que essa insurreição é uma farsa. Primeiro, ao reparar nos apêndices dos balões de texto. As conexões entre o que é dito e as personagens que dizem se canalizam em apêndices compridos alienados das figuras. Sendo assim, ao trazer muitos seres falantes ao mesmo tempo, o procedimento impossibilita que seus enunciados verbais adquiram força verdadeiramente subjetiva.

A posição dos personagens e sua relação com os balões criam um jogo de afastamento e aproximação, terminando por enfatizar ainda mais a natureza solitária de pessoas já separadas pela composição do espaço. Essa relação é complementada pelo balão posicionado no nível mais baixo do quadro e que expõe a fala da personagem que chamou Isaías: “Acontece às vezes...”. O final é amargo, pois explicita que a rebeldia e a insubordinação estão previstas pelos esquemas de poder e são mais uma engrenagem de seu maquinismo.

Esse lastro semântico é favorecido justamente pelo layout da narrativa. No que se refere à separação dos quadros, o processo construído pela faixa irregu- 

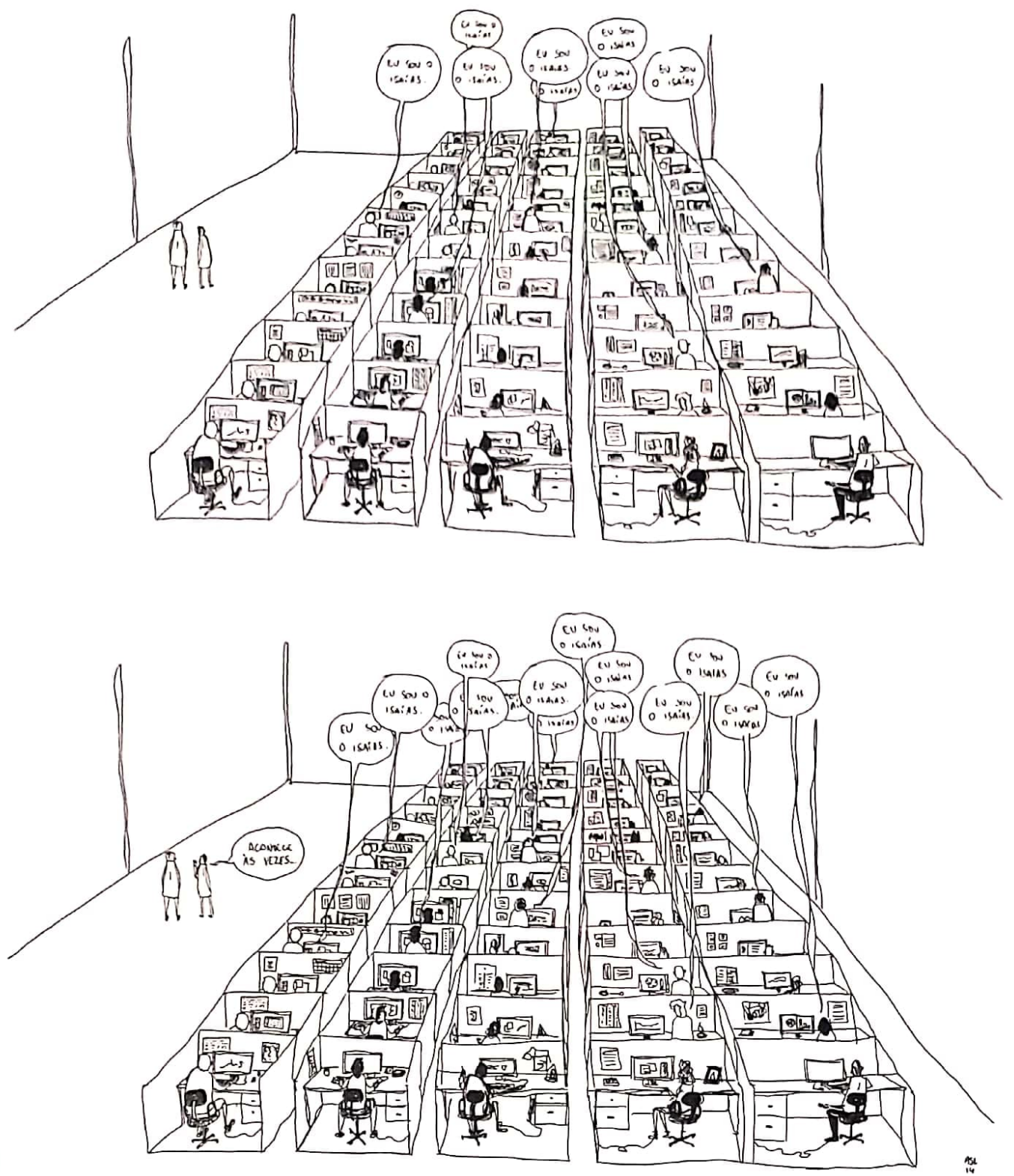

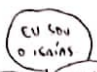
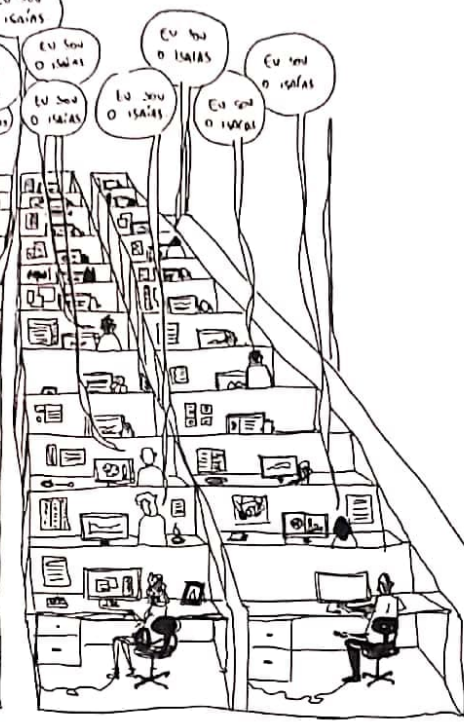

FiguRA 11 
lar branca entre a imagem superior e a inferior, essa ausência de requadro definido entre os quadros, além de confrontar uma vez mais a parte superior da página com a inferior, a partir de uma fronteira indistinta, ainda modula o ritmo de leitura, permite a noção de sequencialidade impressa na sarjeta convencional e obriga o leitor a preencher arbitrariamente a divisão dos quadros neste vazio indefinido. Ao fazer isso, envolve o leitor irremediavelmente no processo de configuração espaçotópica e artrológica, pois ele só existe definido na página quando a lacuna do espaço em branco é compreendida em sua função de apartar e pontuar a ação, sendo fundamental na variação do "ritmo gráfico" (BARBIERI, 2017, p. 148). Como já defendeu Barbara Postema:

\begin{abstract}
A lacuna que significa a partir da sarjeta ainda pode funcionar quando a sarjeta concreta não está lá. A forma dos quadrinhos absorveu a função da sarjeta em um nível que a utiliza mesmo quando não há espaço em branco entre quadros, expandindo as possibilidades da página dos quadrinhos. A função da sarjeta está enraizada na página dos quadrinhos, trazendo significados mesmo quando a sarjeta literal está ausente. A lacuna é necessária na transição que parte da observação do layout para a compreensão da estrutura sequencial da página como uma narrativa em quadrinhos (Postema, 2018, p. 85).
\end{abstract}

Ao investigar os processos pelos quais se separam os itens ao longo da página, nosso olhar se direciona também para outro elemento: a divisão das baias. A organização delas em série e seu formato dividem os funcionários em um esquema que funciona análogo à disposição dos quadros. É mais um tipo de uso metalinguístico do discurso em Lourenço. Neste, como em muitos outros textos do autor (alguns já citados aqui), o enquadramento da cena se processa em um distanciamento fundamental que não define as figuras humanas, apequenando-as diante da amplitude do quadro e/ou do ambiente. Em outras palavras, como na história "Trabalho", as relações espaçotópicas que configuram o layout tratam de serializar as formas humanas por intermédio de zonas nas quais se criam tensões entre a imagem e a espaçotopia, posto que é no contato entre essas duas esferas que se processa a decupagem. De acordo com Groensteen:

Os quadrinhos podem ser comparados a amostras metonímicas que operam sobre um "plano conjunto" virtual, o qual encerra a sequência em sua totalidade tanto espacial quanto temporalmente. O termo decupagem deve então ser entendido literalmente e em relação a duas dimensões: o que é decupado não são apenas momentos do tecido narrativo (os momentos chave da ação), são também vistas parciais, os enquadramentos seletivos que enfocam zonas pertinentes e deixam diversas informações fora de quadro. Roland Barthes lembrava: "mola da atividade é a própria confusão da consecução e da consequência, o que vem depois sendo lido na narrativa como causado por". A narratologia moderna, contudo, cria um modelo de análise estrutural que tende a "descronologicizar" o conteúdo narrativo e a "relogicizar". O que me parece é que a organização 
narrativa própria à história em quadrinhos, ou seja, a maneira como ela distribui as informações por sua duração, excede com grande frequência a lógica do post hoc, ergo propter hoc, usando procedimentos que já são eles mesmos estruturais (GROENSTEEN, 2015, p. 127).

A história "Isaías", se pensada a partir deste raciocínio é, antes de um esquema de causas e consequências narrativas/discursivas, um todo complexo de contatos estruturais/sintéticos, uma verdadeira "forma mental", que compreende uma mundivisão específica. No caso, uma vez mais, partindo de um dura crítica às relações laborais, apresenta um universo que, apesar de iconicamente solidário, como diz Groensteen, se desfaz em um jogo poli-informacional que, no andamento da história, não chega a nenhum lugar semanticamente estável, pois mesmo sua visão crítica e cáustica sobre o trabalho, envolve descrença em relação à capacidade humana de desconectar-se dele. É, por este caminho, um trabalho aberto em todos os níveis, como sustentou Umberto Eco.

Todos esses aspectos convergem para a última história a ser analisada aqui, intitulada "Fabrizio" (LourençO, 2014, p. 52-53). Nela, somos apresentados, em duas páginas, à história da vida do protagonista que nomeia a narrativa. Os quadros da tira têm parênteses debaixo de si, como se estivéssemos diante de questões de múltipla escolha. Em cada um dos momentos decisivos no percurso do sujeito, somos apresentados a algumas possibilidades de sua biografia e acompanhamos, pela marca do "X" na cor azul - a simular uma caneta -, qual delas foi efetivamente seguida. As opções põem alternativas insólitas, excêntricas e esdrúxulas, ao lado de outras previsíveis, convencionais e banais. Por exemplo, em vez de ser playboy ou fazer parte do primeiro casamento gay de São José dos Pinhais, Fabrizio opta por casar com Ana, do mercadinho. No lugar de viver como ninja assassino, rock star, explorador, goleador ou ter uma overdose, o indivíduo decide ser analista de sistemas.

Justamente no quadro que mostra o personagem atuando na sua profissão, temos uma imagem muito parecida com aquela presente na narrativa "Trabalho". Alexandre S. Lourenço insere, mais uma vez, no cotidiano monótono de seu protagonista, a face mais sacrificante do capitalismo: exercer um ofício que, em nenhuma medida, o enobrece. Contudo, nesta história o layout localiza os quadros de uma maneira distinta. Primeiramente as molduras são linhas muito simplificadas e irregulares. Os quadros em nenhum momento entram em contato uns com os outros e flutuam no branco da página. A sarjeta, nesse contexto, é um lacunar que se apresenta à leitura o tempo todo, e essa presença ostensiva promove, após a percepção de cada quadro, um retorno para este universo ainda sem tempo nem espaço, em que os ícones não se situaram nem se sucederam. É esse vazio que representa, mais do que as opções não selecionadas por Fabrizio, aquilo que sua existência é: um conjunto de ações não realizadas e cenas não vistas. Aqui, novamente, tem-se um comentário muito preciso do que é fazer/fruir uma história em quadrinhos, isto é, 

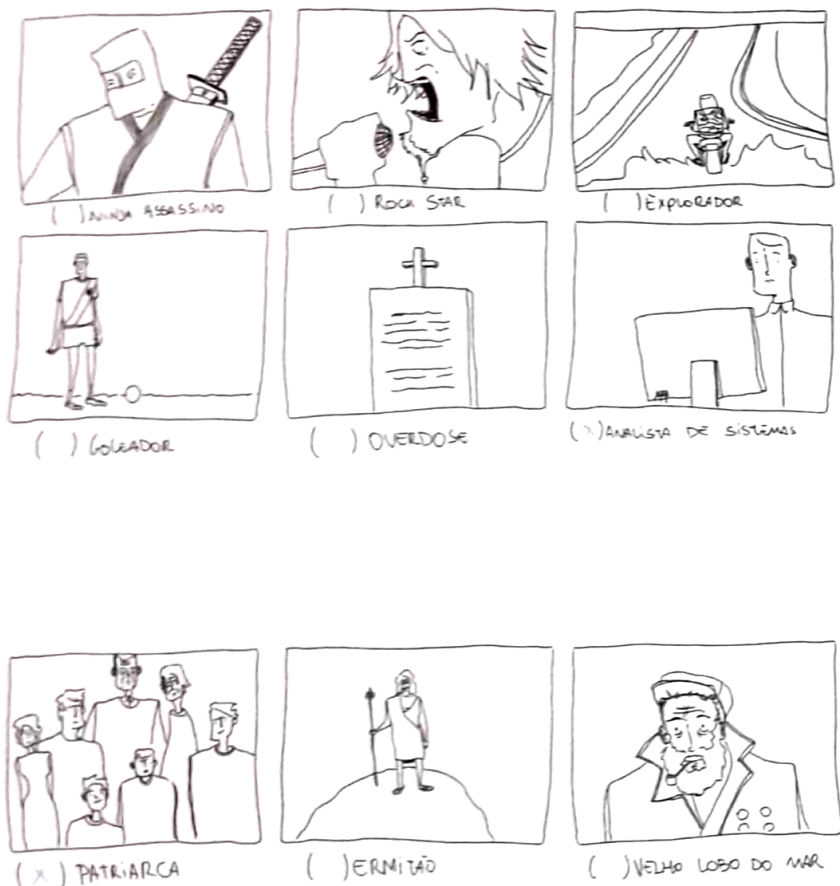

(x) phtriarca

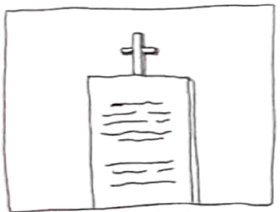

$(x)$ monto Ast. 202

| 53

FIGURA 12 
Quando levamos em conta a composição tudo-junto, forma e expressão viram uma coisa só. O sentido é transmitido não apenas pelo que é retratado, mas também pela estrutura: o tamanho, forma, posição e a relação entre os componentes - importando aí do que eles estão perto e do que não estão. (Assim como sua orientação). Art Spiegelman descreve cada página como uma unidade arquitetônica - ideias que se tornam espaço. Como Goethe, Chris Ware compara os quadrinhos à "música congelada, um espaço para reconstruir a memória dos caminhos bifurcados, tangenciais (e parentéticos), em camadas sobrepostas, desatadas, momentos aninhados em momentos, os quadrinhos têm como abarcar os modos desaplanados nos quais o pensamento se desdobra. Através da sua multiplicidade de abordagens para constituir a experiência, é um meio que pode fornecer a perspectiva superior a partir da qual se iluminam as armadilhas que nós mesmos criamos e propor um modo de... escapar (SousANIs, 2017, p. 66-67).

Esses fragmentos que tentam se mostrar solidários uns com os outros, esta disjunção que se descortina em zonas seriais e sequenciais, essas fronteiras híbridas entre espaço e tempo permitem que os quadrinhos penetrem zonas de sentido inacessíveis para outros sistemas artísticos e que só se configuram enquanto enunciado e enunciável quando nós, os leitores, unimos, organizamos e decidimos. Este é por natureza o locus discursivo de direito da nona arte. Ao focalizar esses procedimentos e incentivar, por um lado, o jogo intericônico do quadro, e, por outro, suas implicações estéticas, os quadrinhos de Alexandre S. Lourenço tem se destacado dentro do panorama dos quadrinhos nacionais contemporâneos. Muitas das leituras propostas aqui podem se estender ao personagem separado da própria cabeça em Você é um babaca, Bernardo ou para o layout provocativo de Boxe. Mas isso é tema para outro trabalho.

\section{Referências}

BArbieri, Daniele. As linguagens dos quadrinhos. São Paulo: Peirópolis, 2017.

Groensteen, Thierry. O sistema os quadrinhos. Rio de Janeiro: Marsupial Editora, 2015 .

Lourenço, Alexandre S. Robô esmaga. São Paulo: JBC, 2014.

Postema, Barbara. Estrutura narrativa nos quadrinhos: construindo sentido a partir de fragmentos. São Paulo: Peirópolis, 2018.

Ramos Paulo. Tiras livres: um novo gênero dos quadrinhos. São Paulo: Marca de Fantasia, 2014.

SousAnIs, Nick. Desaplanar. São Paulo: Veneta, 2017.

Recebido em 18 de abril de 2019.

Aprovado em 27 de outubro de 2019. 


\section{Resumo/Abstract/Resumen}

O layout como fator constitutivo dos quadrinhos: o caso Alexandre S. Lourenço

\section{Daniel Baz dos Santos}

Este artigo discute a obra "Robô esmaga", de Alexandre S. Lourenço, com o intuito de demonstrar como algumas de suas histórias são construídas. Nesse sentido, este trabalho aborda algumas noções teóricas da arte sequencial, com destaque para as reflexões feitas por Thierry Groensteen, Paulo Ramos e Barbara Postema sobre a natureza dos quadrinhos. O uso do layout, os balões de texto, a sarjeta e os conceitos de artrologia e espaçotopia são alguns dos instrumentos envolvidos nesta análise.

Palavras-chave: quadrinhos brasileiros, tira, quadrinhos contemporâneos, teoria dos quadrinhos

Layout as an essential constitutional element in comics: the case of Alexandre. S. Lourenço

\section{Daniel Baz dos Santos}

This article analyses the work "Robô Esmaga", by Alexandre S. Lourenço. With the aim of demonstrating how he constructs his stories. To do so, this study looks at some of the theoretical notions of sequential art, discussing the ideas of Thierry Groensteen, Paulo Ramos and Barbara Postema about the nature of comics. The use of layout, speech bubbles, margins and the concepts of arthrology and the 'spatio-topical system' are some of the resources involved in this analysis.

Keywords: Brazilian comics, comic strip, contemporary comics, comic theory

La disposición de página como factor constituyente de los cómics: el caso Alexandre S. Lourenço

\section{Daniel Baz dos Santos}

Este artículo habla de la obra "Robô Esmaga", de Alexandre s. Lourenço, con la intención de demostrar como son construidas algunas de sus historias. Para ello nos servimos de algunas nociones teóricas del arte secuencial, particularmente las reflexiones hechas por Thierry Groensteen, Paulo Ramos y Barbara postema sobre la naturaleza de los cómics. El uso de la disposición de página, los bocadillos, la calle y los conceptos de artrología y espaciotopía son algunos de los instrumentos utilizados en el análisis.

Palabras clave: cómic brasileño, tiras cómicas, cómic contemporáneo, teoría del cómic. 